\title{
Lithium: a potential therapeutic strategy in obsessive-compulsive disorder by targeting the canonical WNT/ $\beta$ pathway
}

\author{
Alexandre Vallée (iD), Jean-Noël Vallée ${ }^{2}$ and Yves Lecarpentier ${ }^{3}$
}

\begin{abstract}
Obsessive-compulsive disorder (OCD) is a neuropsychiatric disorder characterized b-y recurrent and distinctive obsessions and/or compulsions. The etiologies remain unclear. Recent findings have shown that oxidative stress, inflammation, and the glutamatergic pathway play key roles in the causes of OCD. However, first-line therapies include cognitive-behavioral therapy but only $40 \%$ of the patients respond to this first-line therapy. Research for a new treatment is mandatory. This review focuses on the potential effects of lithium, as a potential therapeutic strategy, on OCD and some of the presumed mechanisms by which lithium provides its benefit properties. Lithium medication downregulates GSK-3 $\beta$, the main inhibitor of the WNT/ $\beta$-catenin pathway. The activation of the WNT/ $\beta$-catenin could be associated with the control of oxidative stress, inflammation, and glutamatergic pathway. Future prospective clinical trials could focus on lithium and its different and multiple interactions in OCD.
\end{abstract}

\section{Introduction}

Obsessive-compulsive disorder (OCD) is a neuropsychiatric disorder that affects around $1-2 \%$ of the population in their lifetime ${ }^{1}$. OCD is characterized by recurrent and distinctive obsessions and/or compulsions and causes significant problems for patients and their families. OCD is one of the most common mental health disorders in the world ${ }^{2}$. OCD reduces the quality of life, increases the recourse of care services, and impairs social functioning. The presence of mood disorders, depression, anxiety, impulse control disorders, sleep disturbance, and personality disorders could be associated with OCD and exhibit comorbid conditions ${ }^{3}$. These comorbidities can be correlated with social difficulties and can have a major impact on health-related quality of life $\mathrm{e}^{4}$. The risk of suicide is increased in $\mathrm{OCD}^{5}$. Efficacious treatments are

Correspondence: Alexandre Vallée (alexandre.g.vallee@gmail.com)

'Department of Clinical Research and Innovation (DRCI), Foch Hospital, 92150, Suresnes, France

${ }^{2}$ Centre Hospitalier Universitaire (CHU) Amiens Picardie, Université Picardie Jules Verne, 80054 Amiens, France

Full list of author information is available at the end of the article needed to face the debilitating nature of $\mathrm{OCD}^{6}$. The etiologies of OCD remain unclear, but there are several functional disorders in many structures such as the brain's orbitofrontal cortex, limbic system, basal ganglia and thalamus, and neurotransmitters ${ }^{7}$.

Nevertheless, the links between neuro-anatomical and biochemical models have not yet been well-established definitively ${ }^{8}$.

In recent years, oxidative stress and free radicals, inflammation ${ }^{10}$, and the glutamatergic pathway ${ }^{11}$ have been shown to play key roles in the causes of OCD.

First-line therapies include cognitive-behavioral therapy ${ }^{12}$. Augmentation strategies with antipsychotics could provide some benefits in at least a third of patients in the case of treatment resistance. Only $40-60 \%$ of the patients respond to first-line therapy and research for new treatment beyond current guidelines is mandatory ${ }^{13}$.

This review focuses on the potential effects of lithium, as a potential therapeutic strategy, on OCD and some of the presumed mechanisms by which lithium provides its beneficial properties.

\section{(c) The Author(s) 2021}

(c) (i) Open Access This article is licensed under a Creative Commons Attribution 4.0 International License, which permits use, sharing, adaptation, distribution and reproduction c. in any medium or format, as long as you give appropriate credit to the original author(s) and the source, provide a link to the Creative Commons license, and indicate if changes were made. The images or other third party material in this article are included in the article's Creative Commons license, unless indicated otherwise in a credit line to the material. If material is not included in the article's Creative Commons license and your intended use is not permitted by statutory regulation or exceeds the permitted use, you will need to obtain permission directly from the copyright holder. To view a copy of this license, visit http://creativecommons.org/licenses/by/4.0/. 
Lithium, which was introduced in 1949 , is the main commonly used drug for the treatment of chronic mental illnesses, such as bipolar disorder, characterized by depressive and manic cycles. Lithium remains the first-line therapy for manic-depressive illness, bipolar disorder ${ }^{14}$, traumatic brain injury ${ }^{15}$, and numerous neurodegenerative diseases, such as Alzheimer's, Huntington's, and Parkinson's diseases ${ }^{16}$. In the acute treatment of mania, the efficacy of lithium is well established ${ }^{17}$. Several studies have shown that prophylactically lithium can reduce manic relapses, even if its efficacy is significantly lower in the reduction of depressive relapses ${ }^{18}$. Moreover, other studies have presented that therapy by lithium could reduce suicides and suicide attempts in patients with mood disorders ${ }^{19}$. Lithium therapeutic mechanisms remain complex, including several pathways and gene expression, such as neurotransmitters and receptors, circadian modulation, ion transport, and signal transduction processes $^{20}$.

Thus, recent advances seem to show that the benefits of lithium extend beyond just the treatment of mood. Neuroprotection against excitotoxicity or brain damage is another role of lithium ${ }^{21}$. However, in contrast, several reports have presented that a high dose of lithium could induce irreversible neurotoxicity effects ${ }^{22}$. Excessive intake or impaired excretion could result in lithium accumulation. Lithium is mainly susceptible to accumulation in bone, muscle, liver, thyroid, and kidney ${ }^{23}$. Dehydration, febrile illness, or gastrointestinal loss can lead to elevated lithium levels in serum ${ }^{24}$. Renal toxicity is more common in patients on chronic lithium therapy with nephrogenic diabetes insipidus ${ }^{25}$. The neurologic effects are hyperreflexia, nystagmus, or ataxia and remain mostly reversible ${ }^{24}$. Other troubles are reversible cardiovascular effects (QT prolongation, intraventricular conduction defects) ${ }^{26}$, gastrointestinal effects ${ }^{27}$, and endocrine effects ${ }^{28}$. But, low doses of lithium are correlated with lower side-effects ${ }^{29}$.

\section{Pathophysiology of OCD \\ $O C D$ and oxidative stress}

The oxidative stress process presents an imbalance between production and elimination of reactive metabolites and free radicals (ROS and RNS $)^{30}$. ROS production is due to cell damages by nitration and oxidation of several lipids, proteins, and DNA. The NADPH oxidase (NOX) enzyme involves ROS by the oxidation of intracellular NDAPH to NADP +. Intracellular and extracellular environmental conditions are modulated by ROS production $^{31}$. Mitochondrial dysfunction associated with excessive ROS production and a diminution in ATP production characterize the oxidative stress process ${ }^{32}$. Inflammation markers, such as leukocytes, are recruited from the damage sites and then participate in the increased uptake of oxygen for the release of ROS and thus its accumulation. NOX, activated by the inflammation process, enhances oxidative stress ${ }^{32,33}$.

The main antioxidants are superoxide dismutase (SOD), glutathione peroxides, and catalase. SOD is synthesized in response to oxidative stress and acts as an antioxidant, but its elevation in intracellular conditions increases cell damage by a generation of $\mathrm{H}_{2} \mathrm{O}_{2}{ }^{34}$. Glutathione is one of the first-line defense against oxidative stress. Glutathione peroxidases are selenoenzymes that catalyze the reduction in hydroperoxide at the expense of gluthatione ${ }^{34}$. The heme-containing enzyme catalase has a major role in the removal of hydrogen peroxide ${ }^{35}$. They protect biomembranes against oxidative attack, lipid peroxidation by $\mathrm{H}_{2} \mathrm{O}_{2}$, and slows down $\mathrm{H}_{2} \mathrm{O}_{2}$-dependent free-radical attack on lipids ${ }^{36}$.

Free radicals (ROS and RNS) induce a decrease in synaptic efficacy ${ }^{37}$ by affecting excitatory and inhibitory synaptic potentials ${ }^{38}$. Free radicals deteriorate membrane lipids by lipid peroxidation, cause ATP depletion, DNA damage and neuronal dysregulation ${ }^{39}$. The brain and nervous system are especially prone to free-radicalinduced damage, due to their highly oxygenated organ function ${ }^{40}$ and low catalase activities ${ }^{41}$. The brain presents a large amount of iron and polyunsaturated fatty acids and a moderate amount of SOD and glutathione peroxides ${ }^{34}$. Several studies have shown that free-radical-mediated neuronal dysregulation plays a key role in the pathophysiology of psychiatric diseases by increased SOD activity levels, such as in schizophrenia ${ }^{42}$. The comorbidity observed in OCD raises this possibility of basal ganglia involvement ${ }^{43}$. Major depression presents increased monoamine oxidase activity and elevated antioxidant levels ${ }^{44}$. Recent studies have shown that SOD levels were significantly higher in OCD patients compared to the control group ${ }^{34}$. A higher production of reactive oxygen metabolites, such as the superoxide anion, affects catalase activity $^{45}$, and an increase in production of hydroxyl ions reduces catalase activity ${ }^{46}$. Numerous studies have shown a link between OCD and oxidative stress by the involvement of free radicals and antioxidant defense ${ }^{34,44}$. Moreover, free radicals damage the cell structure and extracellular matrix compounds by disrupting the genetic structure, oxidative stress, mitochondrial dysfunction, and impaired metabolism? ${ }^{9}$.

\section{$O C D$ and inflammation}

Numerous evidence has shown an important role played by the immune system (i.e. inflammation) in the etiology of psychiatric disorders ${ }^{47}$. The link between the immune system and inflammation in OCD pathophysiology is recent and had emerged in the early nineties ${ }^{11}$. Indeed, the pediatric autoimmune neuropsychiatric disorder associated with group A $\beta$-hemolytic streptococcus 
(GABHS) (PANDAS) and thus the recalled pediatric acute neuropsychiatric syndrome (PANS) have highlighted that several agents rather than streptococcus could be involved in these acute-onset forms of $\mathrm{OCD}^{48}$. The hypothesis for PANS and PANDAS was a link between gangliosides in basal ganglia neurons and the GABHS and/or other agent ${ }^{48}$. Other studies have presented evidence of inflammatory and immune system increase in pediatric OCD by higher monocytes and CD16+ monocytes compared to healthy control subjects ${ }^{49}$.

Nevertheless, the relevance of neuro-inflammation and autoimmunity in OCD seems not limited to subsets of pediatric and acute onset forms of OCD but could be of interest in adults ${ }^{50}$. The role of inflammation in OCD has been strengthened by the higher rate of anti-basal ganglia antibodies (ABGA) in patients with primary OCD versus control subjects ${ }^{51}$. Moreover, significantly increased levels of cytokines and inflammatory agents have been observed in OCD patients, such as IL-2/4/6/10 and TNF$\alpha$, compared to controls ${ }^{52}$. In a recent study using positron emission tomography (PET) imagery, the presence of inflammation in the cortico-striatal-thalamo-cortical circuit was shown to induce microglial cell activation in OCD patients ${ }^{10}$.

\section{$O C D$ and microglial dysregulation}

Microglia are the brain's resident immune cells. They are small cells of macrophage lineage originating from hematopoietic progenitors present in the brain. They can be identified in brain tissue by their expression of numerous macrophage markers ${ }^{53}$. Microglia have been presumed to be quiescent under physiological conditions and activated upon immune stimulation. They act in the regulation of neurogenesis ${ }^{54}$, neuronal function, and homeostasis under physiological conditions and in the absence of inflammation ${ }^{55}$. The dysregulated activation of microglia leads to infiltration of the brain by macrophages under pathological conditions ${ }^{55}$. A specific role for microglia in OCD has been suggested in mouse models ${ }^{56}$. However, this mechanism remains unclear.

\section{$O C D$ and the glutamatergic pathway}

Glutamatergic dysfunction is becoming the principal focus o pharmacological research in the OCD field. Glutamate is an amino acid responsible for the brain's primary excitatory neurotransmission and is considered as the main neurotransmitter within the cortico-striatalthalamic circuit involved in $\mathrm{OCD}^{57}$. Glutamatergic neurons are embedded in every brain circuit in comparison to dopamine and serotonin, which are used by a small minority of neural cells in the brain. Numerous evidence has shown a glutamatergic dysfunction in $\mathrm{OCD}^{11,58}$.

Glutamate is the main excitatory neurotransmitter in the brain and is present in more than $50 \%$ of synapses.
This signaling plays a major role in neuronal plasticity, memory, and learning ${ }^{59}$. Rapid neurotoxicity enhanced by neuronal excitotoxin has been observed with abnormal glutamate levels ${ }^{60}$.

In neurons, glutamate is stored in synaptic vesicles from which it is released. The release of glutamate leads to increased glutamate concentration in the synaptic cleft to bind ionotropic glutamate receptors. The main consistent candidate gene in OCD is the SLC1A1 (solute carrier, family 1 , member 1) gene ${ }^{61}$. SLC1A1 encodes for the neuronal excitatory $\mathrm{Na}+$-dependent amino acid transporter 3 (EAAT3). EAAT1 and EAAT2 are the main astrocyte glutamate transporters, whereas EAAT3 is the major neuronal glutamate transporter. Glutamate is converted into glutamine in astrocytes and thus releases it. Then, glutamine is taken up by neurons to be reconverted into glutamate ${ }^{62}$. The role of the EAAT3 is to control glutamate spillover, which affects pre-synaptic $N$-methyl- $D$-aspartate (NMDA) and metabotropic glutamate receptors activity ${ }^{63,64}$. EAAT3 activity is dysregulated by the overexpression of GSK- $3 \beta^{65}$.

Increased levels of glutamate in adult unmedicated patients with OCD have been shown in cerebrospinal fluid (CSF) ${ }^{66,67}$. Moreover, studies based on magnetic resonance spectroscopy (MRS) have observed increased glutamate and related components in brain areas, including central nodes of the cortico-striatal-thalamocortical circuit in OCD patients ${ }^{11,68}$. In addition, genetic studies have also involved a correlation of glutamatergic genes with $\mathrm{OCD}^{69}$.

\section{Activation of the canonical WNT pathway by lithium: a potential therapeutic strategy Lithium and GSK-3 $\beta$}

A recent study has observed that mutant murine models of OCD presented increased GSK-3 $\beta$ activity and thus its inhibition could be a treatment of perseverative behaviors ${ }^{70}$.

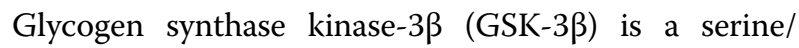
threonine kinase that is involved in numerous intracellular signaling pathways. Dysfunction of GSK-3 $\beta$ is involved in the pathogenesis of several diseases, including neuropsychiatric disorders ${ }^{71}$. GSK-3 $\beta$ is a regulator of several pathways such as inflammation, neuronal polarity, or either cell membrane signaling ${ }^{72}$. GSK3 $\beta$ is known to be the major inhibitor of the canonical $\mathrm{WNT} / \beta$-catenin pathway $^{73}$. The name WNT is derived from Wingless drosophila melanogaster and its mouse homolog Int. The WNT pathway is involved in numerous signaling and regulating pathways, such as embryogenesis, cell proliferation, migration and polarity, apoptosis, and organogenesis $^{74}$. However, during numerous pathological states, the WNT pathway can be dysregulated, such as in inflammatory, metabolic and neurological disorders, 


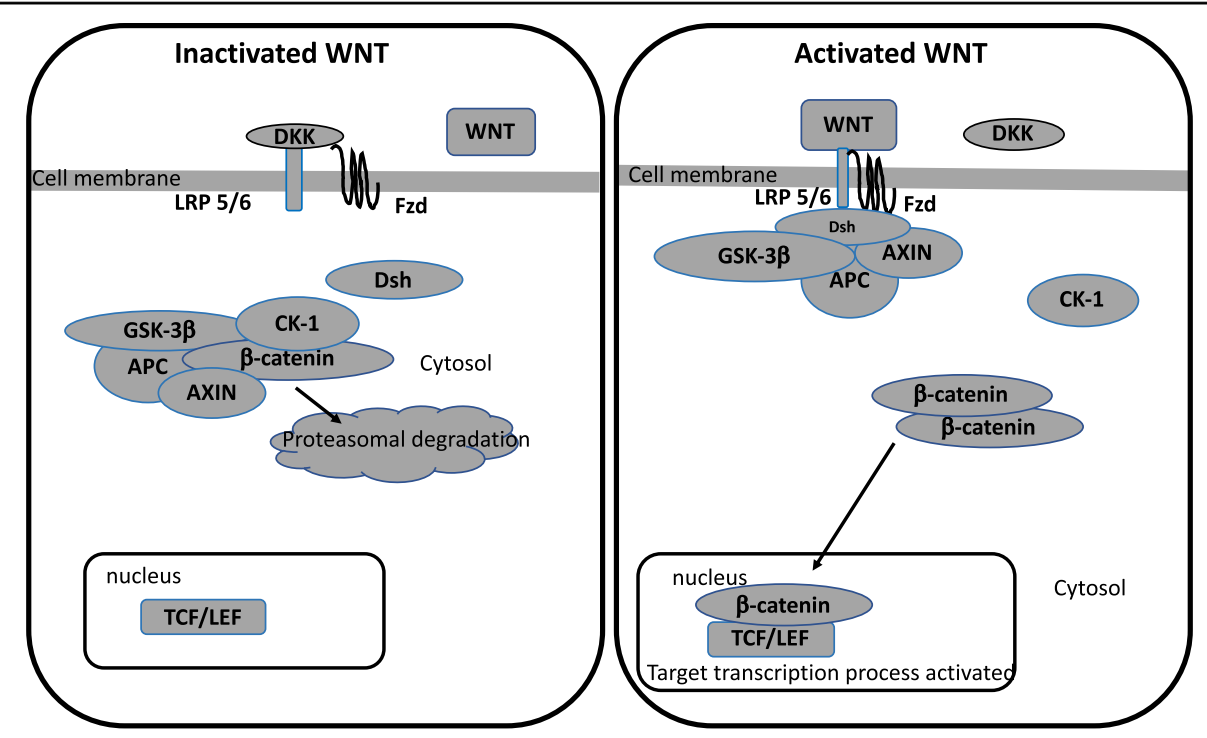

Fig. 1 WNT pathway activation and inhibition.

tissue fibrosis, and cancers ${ }^{75}$. GSK-3 $\beta$ downregulates the canonical WNT/ $\beta$-catenin pathway by inhibiting $\beta$-catenin cytosolic stabilization and its translocation in the nucleus ${ }^{76}$. Moreover, several studies have shown a link between neuroinflammation and the augmentation of the GSK-3 $\beta$ activity and in parallel the decrease of the WNT/ $\beta$-catenin pathway and the protein kinase B (Akt) pathway (Fig. 1$)^{77}$.

Lithium at concentrations of 1-2 mM can inhibit GSK$3 \beta$ activity $^{78-80}$. Lithium reduces GSK-3 $\beta$ activity by increasing the inhibitory phosphorylation of GSK3 $\beta$ and through direct activation of the Akt pathway. The activation of Akt modulates forkhead bow class O (FOXO) and $\mathrm{Bcl}-2$ associated death protein (Bad) (a pro-apoptotic protein of the Bcl-2 family) ${ }^{81,82}$.

\section{Lithium and the WNT/B-catenin pathway}

Therapeutic concentrations of the GSK-3 $\beta$ inhibitor lithium lead to the increase in $\beta$-catenin levels ${ }^{83,84}$ and then promotes $\beta$-catenin transcriptional activity ${ }^{16,85}$. In the brain of a mouse, the over-expression of $\beta$-catenin levels mimics the anti-depressant-like effects of lithium ${ }^{86}$, while the knockout of $\beta$-catenin leads to a depression-like phenotype $^{87,88}$.

\section{Lithium in $O C D$}

\section{Lithium and oxidative stress}

The energy and glucose metabolisms involved during oxidative stress are mainly regulated by the intracellular FOXO transcription factors (FOXO1, 3a, 4) ( $^{89}$. The interaction between $\beta$-catenin and FOXO transcription factors promotes cell quiescence and cell cycle arrest. B-catenin blocks its transcriptional complex with TCF/LEF through the interaction with FOXO-induced $\mathrm{ROS}^{90}$. B-cateni does not translocate to the nucleus and thus accumulates in the cytosol, leading to the inactivation of the $\mathrm{WNT} / \beta$-catenin pathway ${ }^{91,92}$. A previous study has found that lithium can reduce FOXO3a transcriptional activity and can decrease the level of active FOXO3a ${ }^{93}$. Thus, by inactivating GSK3- $\beta$, activating the $\mathrm{WNT} / \beta$-catenin pathway, and reducing the FOXO, lithium could participate in the reduction of oxidative stress in OCD.

Furthermore, several in vitro studies have shown that lithium administration could inhibit hydrogen peroxideinduced cell death as well as obstruct lipid peroxidation and protein oxidation in cortical cells ${ }^{94-99}$. Moreover, lithium can act as an anti-oxidant by increasing the CHS levels in neurons of rat dopaminergic N2 $7^{95,99}$.

\section{Lithium and inflammation}

Through the inhibition of GSK-3 $\beta$ and thus the upregulation of the $\mathrm{WNT} / \beta$-catenin pathway, the lithium administration could involve a diminution of the neuroinflammation by acting on the NF- $\varkappa \mathrm{B}$ pathway. The activation of the WNT pathway cascade restrains inflammation and leads to neuroprotection via interactions between microglia/macrophages and astrocytes (Fig. 2) ${ }^{100,101}$.

Several studies have shown negative crosstalk between the $\mathrm{WNT} / \beta$-catenin pathway and the NF- $\varkappa \mathrm{B}$ signaling pathway ${ }^{102}$. The NF- $\varkappa \mathrm{B}$ transcription factor family consists of five members in the cytosol under non-activated conditions: NF- $x$ B1 (p50/p105), NF- $x$ B 2 (p52/p100), RelA (p65), RelB, and c-Rel ${ }^{103}$. B-CATENIN can form a complex with RelA and p50 to decrease the activity of the NF- $\varkappa B$ signaling ${ }^{104}$. Moreover, by interacting with the PI3K, $\beta$-catenin inhibits 


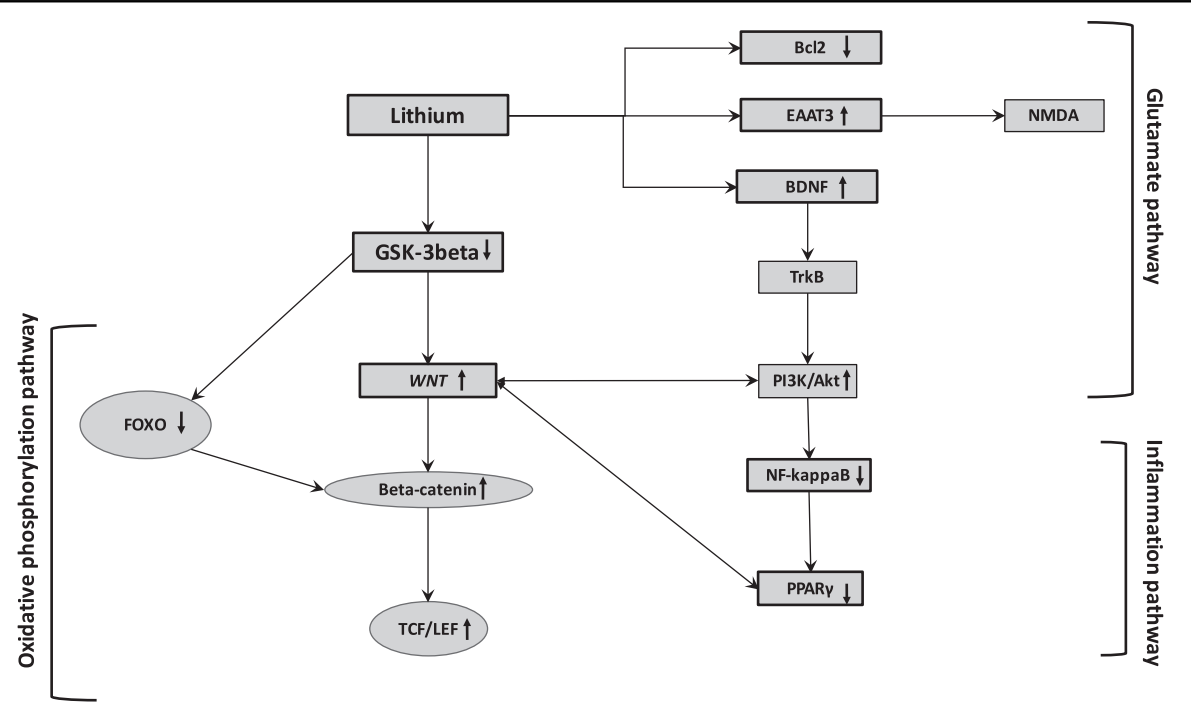

Fig. 2 Lithium interactions with oxidative stress, inflammation, and glutamatergic pathways.

the functional activity of NF- $\varkappa \mathrm{B}^{105}$. This inhibitory function of $\beta$-catenin on NF- $\varkappa B$ activity has been observed in numerous cell types, such as fibroblasts, epithelial cells, hepatocytes, and osteoblasts ${ }^{102}$. In parallel, the overactivation of GSK-3 $\beta$ leads to an inhibition of the $\beta$-catenin and then activation of the NF- $\varkappa$ B pathway ${ }^{106}$. The potential protective action of $\beta$-catenin was due to the activation of the PI3K/Akt pathway and thus the reduction of TLR4driven inflammatory response in hepatocytes ${ }^{107}$. NF- $\varkappa \mathrm{B}$ activation leads to the inhibition of the complex $\beta$-catenin/ TCF/LEF by the upregulation of LZTS2 in cancer cells ${ }^{108}$. DKK, a WNT inhibitor, was a target gene of the NF- $x \mathrm{~B}$ pathway leading to a negative feedback to diminish the $\beta$-catenin signaling ${ }^{109}$.

A recent study has presented that the WNT pathway appeared to be one of the main mechanisms of the action of lithium in adipose cells, and this interaction is done by the inhibition of PPARy expression ${ }^{110}$. PPARs are ligandactivated transcription factors that bind PPRE (PPARresponse elements). PPARs are involved in numerous pathophysiological processes, such as cell differentiation, protein metabolism, lipids metabolism, carcinogenesis $^{111,112}$, adipocyte differentiation, insulin sensitivity, and inflammation ${ }^{113,114}$. PPARy ligands, such as thiazolidinediones (TZDs), are able to decrease inflammatory activity $^{115}$.

A negative crosstalk has been well described between PPAR $\gamma$ and the WNT pathway ${ }^{32,73,116,117}$. The PI3K/Akt pathway, which is positively induced by $\beta$-catenin ${ }^{118,119}$, acts by phosphorylating GSK-3 $\beta$ to negatively regulate PPAR $\gamma$ expression ${ }^{120}$. PPAR $\gamma$ agonists decrease $\beta$-catenin expression by overactivating GSK- $3 \beta^{121}$. Moreover, PPAR $\gamma$ agonists activate Dickkopf-1 (DKK1) activity to decrease the canonical $\mathrm{WNT} / \beta$-catenin pathway and then inhibit fibroblast differentiation ${ }^{122}$. Furthermore, PPAR $\gamma$ agonists activate GSK-3 $\beta$ to decrease $\beta$-catenin expression $^{121}$.

\section{Lithium and the glutamatergic pathway}

Lithium administration has been also associated with an influence on the levels of proapoptotic proteins. Bax, named $\mathrm{Bcl}-2$ associated $\mathrm{C}$ protein, is a key modulator promoting apoptosis by binding to and antagonizing the $\mathrm{Bcl}-2$ protein. The tumor suppressor protein, $\mathrm{p} 53$, targets $\mathrm{Bcl}-2$ and Bax and then promotes growth arrests and cell death in response to cell damage (Fig. 2) ${ }^{123}$.

Several studies have demonstrated that the neuroprotective effects of lithium could be attributed to increased Bcl-2 levels. Indeed, lithium therapy of cultured cerebellar granule cells increased mRNA and protein levels of Bcl-2, and the $\mathrm{Bcl}-2 / \mathrm{Bax}$ protein level ratio increased by 5 -fold after treatment duration for 5-7 days ${ }^{124}$. The increase in Bcl-2 expression leads to neurogenesis in the hippocampus and entorhinal cortex in mice by the increase of axon diameters and neurite growth on the CA3 area of the hippocampus and increased myelination in the entorhinal cortex $^{125}$. Lithium can also act by stimulating antiapoptotic-increasing $\mathrm{Bcl}-2$ levels and reducing $\mathrm{Bax}^{126}$. The phosphorylation of $\mathrm{Bcl} 2$ at serine 70 is needed for a complete anti-apoptotic function ${ }^{127}$ and lithium has this ability $^{128}$. Lithium inhibits Bcl-2 dephosphorylation and caspase-2 activation through the reduction of the protein phosphatase-2A activity ${ }^{128}$.

Glutamate excitotoxicity has been associated with the upregulation of Bax and p53 and the downregulation of Bcl- $2^{124}$. The apoptosis attributed to glutamate was preceded by the increase in activator protein-1 (AP-1) caused by the activation of c-Jun $\mathrm{N}$-terminal kinase (JNK) and 
p38 mitogen-activated protein kinase (MAP kinase) and phosphorylation of c-Jun and $\mathrm{p} 53^{129}$.

By inhibiting GSK-3 $\beta$ activity, lithium acts as a powerful regulator of EAAT3 and thus of the regulation of NMDA receptors ${ }^{130}$. Moreover, a direct potential way could be the inhibition of presynaptic NMDA receptors and thus the activation of postsynaptic AMPA receptors by the release of glutamate. This mechanism is followed by the activation of the influx of calcium and secretion of brain-derived neurotrophic factor (BDNF). Lithium stimulated the release of the excitatory neurotransmitter, glutamate, from cerebral cortex slices ${ }^{131}$. This release was accompanied by an increase in inositol 1,4,5-trisphosphate $\left[\operatorname{Ins}(1,4,5) P_{3}\right]$ accumulation. The increase in $\operatorname{Ins}(1,4,5) P_{3}$ accumulation was caused by the selective activation of the N-methyl-D-aspartate (NMDA) receptor/channel by glutamate. Activation of the NMDA receptor is known to cause increased $\operatorname{Ins}(1,4,5) P_{3}$ accumulation $^{132}$. Thus, BDNF stimulates the receptor tyrosine kinase $B(\operatorname{TrkB})$, leading to neuronal survival and differentiation ${ }^{133}$.

Activated BDNF-TrkB signaling leads to stimulation of the Akt/mTOR pathway, causing activation of the WNT/ $\beta$-catenin pathway and enhancing synaptic proteins ${ }^{134}$. The few therapeutic levels of lithium activate the BDNFTrkB signaling and then the Akt/mTOR signaling to protect neurons from glutamate excitotoxicity ${ }^{135}$. Lithium inhibits excessive glutamate, NMDA receptor-mediated calcium influx in neurons and reduces NR2B subunit tyrosine phosphorylation by the Src/Fyn kinase ${ }^{136}$.

PPARy antagonists can block the increase of PPARy DNA binding activity and antioxidant enzymatic activities (SOD), inhibiting the protection of PPAR $\gamma$ activation in OGD-exposed neurons ${ }^{137}$. Other mechanisms by which these PPAR $\gamma$ agonists prevent oxidative stress include a decrease in iNOS activity, NFKB blockade, inhibition of TNF- $\alpha$ release, or activation of nuclear factor (erythroidderived 2)-like $2(\mathrm{Nrf2})^{138}$. By the negative crosstalk between WNT and PPAR $\gamma$, lithium administration, by inhibiting the GSK-3 $\beta$ could act as a PPAR $\gamma$ antagonist and lead to an increase in the WNT pathway, resulting in diminution of oxidative stress.

\section{Conclusion}

Currently, few studies have studied lithium as a possible alternative therapeutic way to treat OCD patients. However, in low doses, lithium may appear to be interesting against OCD because of its potential inhibitory effect on oxidative stress, inflammation, and the glutamatergic pathway.

No study has still reported the expression of the WNT/ $\beta$ pathway in OCD. Nevertheless, the overactivity of the GSK$3 \beta$, the main inhibitor of the WNT pathway, in OCD patients is consistent with a downregulation of the WNT pathway in this disease. By stimulating the $\mathrm{WNT} / \beta$ pathway, through the inhibition of GSK-3 $\beta$, lithium could be an innovative therapeutic way in OCD. Future prospective studies could focus on lithium and its different and multiple interactions in OCD.

\section{Author details}

'Department of Clinical Research and Innovation (DRCI), Foch Hospital, 92150, Suresnes, France. ${ }^{2}$ Centre Hospitalier Universitaire (CHU) Amiens Picardie, Université Picardie Jules Verne, 80054 Amiens, France. ${ }^{3}$ Centre de Recherche Clinique, Grand Hôpital de l'Est Francilien (GHEF), 77100 Meaux, France

\section{Author contributions}

All authors listed have contributed to the work and approved it for submission to publication.

\section{Conflict of interest}

The authors declare that the research was conducted in the absence of any commercial or financial relationship that could be construed as a potential conflict of interest.

\section{Publisher's note}

Springer Nature remains neutral with regard to jurisdictional claims in published maps and institutional affiliations.

Received: 18 November 2020 Revised: 26 February 2021 Accepted: 19 March 2021

Published online: 07 April 2021

\section{References}

1. Ruscio, A. M., Stein, D. J., Chiu, W. T. \& Kessler, R. C. The epidemiology of obsessive-compulsive disorder in the National Comorbidity Survey Replication. Mol. Psychiatry 15, 53-63 (2010).

2. De Putter, L. M. S. \& Koster, E. H. W. The effects of obsessive-compulsive symptoms and disorder-relevant stimuli on the dynamics of selective attention. J. Obsessive-Compuls. Relat. Disord. 15, 74-84 (2017).

3. Termine, C., Selvini, C., Rossi, G. \& Balottin, U. Emerging treatment strategies in tourette syndrome: what's in the pipeline? Int. Rev. Neurobiol. 112, 445-480 (2013).

4. Müller-Vahl, K. et al. Health-related quality of life in patients with gilles de la Tourette's syndrome. Mov. Disord. J. Mov. Disord. Soc. 25, 309-314 (2010).

5. Fernández de la Cruz, L. et al. Suicide in obsessive-compulsive disorder: a population-based study of 36788 Swedish patients. Mol. Psychiatry 22, 1626-1632 (2017).

6. McHugh, R. K., Whitton, S. W., Peckham, A. D., Welge, J. A. \& Otto, M. W. Patient preference for psychological vs pharmacologic treatment of psychiatric disorders: a meta-analytic review. J. Clin. Psychiatry 74, 595-602 (2013).

7. Bokor, G. \& Anderson, P. D. Obsessive-compulsive disorder. J. Pharm. Pract. 27, 116-130 (2014).

8. Bloch, M. H. et al. Meta-analysis: hoarding symptoms associated with poor treatment outcome in obsessive-compulsive disorder. Mol. Psychiatry 19, 1025-1030 (2014).

9. Alici, D. et al. Evaluation of oxidative metabolism and oxidative DNA damage in patients with obsessive-compulsive disorder. Psychiatry Clin. Neurosci. 70, 109-115 (2016).

10. Attwells, S. et al. Inflammation in the neurocircuitry of obsessive-compulsive disorder. JAMA Psychiatry 74, 833-840 (2017).

11. Grassi, G. \& Pallanti, S. Current and up-and-coming pharmacotherapy for obsessive-compulsive disorder in adults. Expert Opin. Pharmacother. 19, 1541-1550 (2018).

12. Fineberg, N. A. et al. Obsessive-compulsive disorder (OCD): practical strategies for pharmacological and somatic treatment in adults. Psychiatry Res. 227, 114-125 (2015).

13. Pallanti, S., Grassi, G. \& Cantisani, A. Emerging drugs to treat obsessivecompulsive disorder. Expert Opin. Emerg. Drugs 19, 67-77 (2014).

14. Lähteenvuo, M. et al. Real-world effectiveness of pharmacologic treatments for the prevention of rehospitalization in a Finnish nationwide cohort of patients with bipolar disorder. JAMA Psychiatry 75, 347-355 (2018). 
15. Leeds, P. R. et al. A new avenue for lithium: intervention in traumatic brain injury. ACS Chem. Neurosci. 5, 422-433 (2014).

16. Marmol, F. Lithium: bipolar disorder and neurodegenerative diseases possible cellular mechanisms of the therapeutic effects of lithium. Prog. Neuropsychopharmacol. Biol. Psychiatry 32, 1761-1771 (2008).

17. Young, A. H. \& Hammond, J. M. Lithium in mood disorders: increasing evidence base, declining use? Br. J. Psychiatry J. Ment. Sci. 191, 474-476 (2007).

18. Smith, L. A., Cornelius, V., Warnock, A., Bell, A. \& Young, A. H. Effectiveness of mood stabilizers and antipsychotics in the maintenance phase of bipolar disorder: a systematic review of randomized controlled trials. Bipolar Disord. $\mathbf{9}$ 394-412 (2007).

19. Baldessarini, R. J. et al. Decreased risk of suicides and attempts during longterm lithium treatment: a meta-analytic review. Bipolar Disord. 8, 625-639 (2006).

20. Pisanu, C., Melis, C. \& Squassina, A. Lithium pharmacogenetics: where do we stand? Drug Dev. Res. 77, 368-373 (2016).

21. Zhu, Z.-F., Wang, Q.-G., Han, B.-J. \& William, C. P. Neuroprotective effect and cognitive outcome of chronic lithium on traumatic brain injury in mice. Brain Res. Bull. 83, 272-277 (2010).

22. Donaldson, I. M. \& Cuningham, J. Persisting neurologic sequelae of lithium carbonate therapy. Arch. Neurol. 40, 747-751 (1983).

23. Horton, S., Tuerk, A., Cook, D., Cook, J. \& Dhurjati, P. Maximum recommended dosage of lithium for pregnant women based on a PBPK model for lithium absorption. Adv. Bioinforma. 2012, 352729 (2012).

24. Ott, M., Stegmayr, B., Salander Renberg, E. \& Werneke, U. Lithium intoxication: incidence, clinical course and renal function - a population-based retrospective cohort study. J. Psychopharmacol. Oxf. Engl. 30, 1008-1019 (2016).

25. Erden, A. et al. Lithium intoxication and nephrogenic diabetes insipidus: a case report and review of literature. Int. J. Gen. Med. 6, 535-539 (2013).

26. Canan, F. et al. Lithium intoxication related multiple temporary ecg changes: A case report. Cases J. 1, 156 (2008).

27. Mohandas, E. \& Rajmohan, V. Lithium use in special populations. Indian J. Psychiatry 49, 211-218 (2007).

28. Kibirige, D., Luzinda, K. \& Ssekitoleko, R. Spectrum of lithium induced thyroid abnormalities: a current perspective. Thyroid Res. 6, 3 (2013).

29. Abou-Saleh, M. T. \& Coppen, A. The efficacy of low-dose lithium: clinical, psychological and biological correlates. J. Psychiatr. Res. 23, 157-162 (1989).

30. Duracková, Z. Some current insights into oxidative stress. Physiol. Res. 59, 459-469 (2010).

31. Jabs, T. Reactive oxygen intermediates as mediators of programmed cell death in plants and animals. Biochem Pharm. 57, 231-245 (1999).

32. Vallée, A. \& Lecarpentier, Y. Crosstalk between peroxisome proliferatoractivated receptor gamma and the canonical WNT/ $\beta$-catenin pathway in chronic inflammation and oxidative stress during carcinogenesis. Front Immunol. 9, 745 (2018).

33. Weyemi, U. et al. ROS-generating NADPH oxidase NOX4 is a critical mediator in oncogenic $\mathrm{H}$-Ras-induced DNA damage and subsequent senescence. Oncogene 31, 1117-1129 (2012).

34. Behl, A., Swami, G., Sircar, S. S., Bhatia, M. S. \& Banerjee, B. D. Relationship of possible stress-related biochemical markers to oxidative/antioxidative status in obsessive-compulsive disorder. Neuropsychobiology 61, 210-214 (2010).

35. Simon, R. H., Scoggin, C. H. \& Patterson, D. Hydrogen peroxide causes the fatal injury to human fibroblasts exposed to oxygen radicals. J. Biol. Chem. 256, 7181-7186 (1981).

36. Ursini, F. et al. Diversity of glutathione peroxidases. Methods Enzymol. 252 38-53 (1995)

37. Rana, S. V. S., Allen, T. \& Singh, R. Inevitable glutathione, then and now. Indian J. Exp. Biol. 40, 706-716 (2002).

38. Pellmar, T. C. Peroxide alters neuronal excitability in the CA1 region of quinea-pig hippocampus in vitro. Neuroscience 23, 447-456 (1987).

39. Halliwell, B. Oxidants and human disease: some new concepts. FASEB J. Publ. Fed. Am. Soc. Exp. Biol. 1, 358-364 (1987).

40. Pellmar, T. C., Neel, K. L. \& Lee, K. H. Free radicals mediate peroxidative damage in guinea pig hippocampus in vitro. J. Neurosci. Res. 24, 437-444 (1989).

41. Paul, L. A., Fulton, A. M. \& Heppner, G. H. Reactive oxygen-mediated damage to murine mammary tumor cells. Mutat. Res. 215, 223-234 (1989).

42. Graham, D. G. Oxidative pathways for catecholamines in the genesis of neuromelanin and cytotoxic quinones. Mol. Pharm. 14, 633-643 (1978).
43. Yao, J. K., Reddy, R. \& van Kammen, D. P. Reduced level of plasma antioxidant uric acid in schizophrenia. Psychiatry Res. 80, 29-39 (1998).

44. Kuloglu, M. et al. Antioxidant enzyme activities and malondialdehyde levels in patients with obsessive-compulsive disorder. Neuropsychobiology 46, 27-32 (2002).

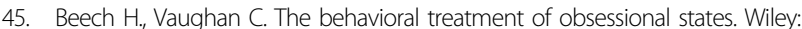
london, 1970.

46. Pigeolet, E. et al. Glutathione peroxidase, superoxide dismutase, and catalase inactivation by peroxides and oxygen derived free radicals. Mech. Ageing Dev. 51, 283-297 (1990).

47. Khandaker, G. M., Dantzer, R. \& Jones, P. B. Immunopsychiatry: important facts. Psychol. Med. 47, 2229-2237 (2017).

48. Chiarello, F., Spitoni, S., Hollander, E., Matucci Cerinic, M. \& Pallanti, S. An expert opinion on PANDAS/PANS: highlights and controversies. Int. J. Psychiatry Clin. Pr. 21, 91-98 (2017).

49. Rodríguez, N. et al. Inflammatory dysregulation of monocytes in pediatric patients with obsessive-compulsive disorder. J. Neuroinflammation 14, 261 (2017).

50. Mataix-Cols, D. et al. A total-population multigenerational family clustering study of autoimmune diseases in obsessive-compulsive disorder and tourette's/chronic tic disorders. Mol. Psychiatry 23, 1652-1658 (2018).

51. Pearlman, D. M., Vora, H. S., Marquis, B. G., Najjar, S. \& Dudley, L. A. Antibasal ganglia antibodies in primary obsessive-compulsive disorder: systematic review and meta-analysis. Br. J. Psychiatry J. Ment. Sci. 205, 8-16 (2014).

52. Rao, N. P. et al. Plasma cytokine abnormalities in drug-naïve, comorbidity-free obsessive-compulsive disorder. Psychiatry Res. 229, 949-952 (2015).

53. Wolf, S. A., Boddeke, H. W. G. M. \& Kettenmann, H. Microglia in physiology and disease. Annu Rev. Physiol. 79, 619-643 (2017).

54. Sierra, A. et al. Microglia shape adult hippocampal neurogenesis through apoptosis-coupled phagocytosis. Cell Stem Cell. 7, 483-495 (2010).

55. Frick, L. R., Williams, K. \& Pittenger, C. Microglial dysregulation in psychiatric disease. Clin. Dev. Immunol. 2013, 608654 (2013).

56. Greer, J. M. \& Capecchi, M. R. Hoxb8 is required for normal grooming behavior in mice. Neuron 33, 23-34 (2002).

57. Ting, J. T. \& Feng, G. Neurobiology of obsessive-compulsive disorder: insights into neural circuitry dysfunction through mouse genetics. Curr. Opin. Neurobiol. 21, 842-848 (2011).

58. Marinova, Z., Chuang, D.-M. \& Fineberg, N. Glutamate-modulating drugs as a potential therapeutic strategy in obsessive-compulsive disorder. Curr. Neuropharmacol. 15, 977-995 (2017).

59. Javitt, D. C. et al. Translating glutamate: from pathophysiology to treatment. Sci. Transl. Med 3, 102mr2 (2011).

60. Sanacora, G., Zarate, C. A., Krystal, J. H. \& Manji, H. K. Targeting the glutamatergic system to develop novel, improved therapeutics for mood disorders. Nat. Rev. Drug Disco. 7, 426-437 (2008).

61. Arnold, P. D., Sicard, T., Burroughs, E., Richter, M. A. \& Kennedy, J. L. Glutamate transporter gene SLC1A1 associated with obsessive-compulsive disorder. Arch. Gen. Psychiatry 63, 769-776 (2006).

62. Daikhin, Y. \& Yudkoff, M. Compartmentation of brain glutamate metabolism in neurons and glia. J. Nutr. 130, 1026S-1031SS (2000).

63. Scimemi, A., Tian, H. \& Diamond, J. S. Neuronal transporters regulate glutamate clearance, NMDA receptor activation, and synaptic plasticity in the hippocampus. J. Neurosci. J. Soc. Neurosci. 29, 14581-14595 (2009).

64. Wu, K., Hanna, G. L., Rosenberg, D. R. \& Arnold, P. D. The role of glutamate signaling in the pathogenesis and treatment of obsessive-compulsive disorder. Pharm. Biochem Behav. 100, 726-735 (2012).

65. Kim, M.-S. et al. Nerve growth factor (NGF) regulates activity of nuclear factor of activated T-cells (NFAT) in neurons via the phosphatidylinositol 3-kinase (PI3K)-Akt-glycogen synthase kinase $3 \beta$ (GSK3 $\beta$ ) pathway. J. Biol. Chem. 289 31349-31360 (2014)

66. Ting, J. T. \& Feng, G. Glutamatergic synaptic dysfunction and obsessivecompulsive disorder. Curr. Chem. Genomics. 2, 62-75 (2008).

67. Chakrabarty, K., Bhattacharyya, S., Christopher, R. \& Khanna, S. Glutamatergic dysfunction in OCD. Neuropsychopharmacol. Publ. Am. Coll. Neuropsychopharmacol. 30, 1735-1740 (2005).

68. Starck, G. et al. A $1 \mathrm{H}$ magnetic resonance spectroscopy study in adults with obsessive compulsive disorder: relationship between metabolite concentrations and symptom severity. J. Neural Transm. Vienna Austria $1996 \mathbf{1 1 5}$ 1051-1062 (2008). 
69. Pauls, D. L., Abramovitch, A., Rauch, S. L. \& Geller, D. A. Obsessive-compulsive disorder: an integrative genetic and neurobiological perspective. Nat. Rev. Neurosci. 15, 410-424 (2014).

70. Thompson, S. L. \& Dulawa, S. C. Dissecting the roles of $\beta$-arrestin2 and GSK-3 signaling in 5-HT1BR-mediated perseverative behavior and prepulse inhibition deficits in mice. Plos ONE. 14, e0211239 (2019).

71. Giese, K. P. GSK-3: a key player in neurodegeneration and memory. IUBMB Life. 61, 516-521 (2009).

72. Hur, E.-M. \& Zhou, F.-Q. GSK3 signalling in neural development. Nat. Rev. Neurosci. 11, 539-551 (2010).

73. Vallée A., Vallée J.-N., Lecarpentier Y. PPARy agonists: potential treatment for autism spectrum disorder by inhibiting the canonical WNT/ $\beta$-catenin pathway. Mol. Psychiatry 2018. https://doi.org/10.1038/s41380-018-0131-4.

74. Loh, K. M., van Amerongen, R. \& Nusse, R. Generating cellular diversity and spatial form: Wnt signaling and the evolution of multicellular animals. Dev. Cell .38, 643-655 (2016).

75. Oren, O. \& Smith, B. D. Eliminating cancer stem cells by targeting embryonic signaling pathways. Stem Cell Rev. 13, 17-23 (2017).

76. Libro, R., Bramanti, P. \& Mazzon, E. The role of the Wnt canonical signaling in neurodegenerative diseases. Life Sci. 158, 78-88 (2016).

77. Sharma, C., Pradeep, A., Wong, L., Rana, A. \& Rana, B. Peroxisome proliferatoractivated receptor gamma activation can regulate beta-catenin levels via a proteasome-mediated and adenomatous polyposis coli-independent pathway. J. Biol. Chem. 279, 35583-35594 (2004).

78. Bauer, M., Alda, M., Priller, J. \& Young, L. T., International group for the study of lithium treated patients (IGSLI). Implications of the neuroprotective effects of lithium for the treatment of bipolar and neurodegenerative disorders. Pharmacopsychiatry 36, S250-S254 (2003). Suppl 3.

79. Rowe, M. K. \& Chuang, D.-M. Lithium neuroprotection: molecular mechanisms and clinical implications. Expert Rev. Mol. Med. 6, 1-18 (2004).

80. Rowe, M. K., Wiest, C. \& Chuang, D.-M. GSK-3 is a viable potential target for therapeutic intervention in bipolar disorder. Neurosci. Biobehav Rev. 31 920-931 (2007).

81. Alural, B., Ozerdem, A., Allmer, J., Genc, K. \& Genc, S. Lithium protects against paraquat neurotoxicity by NRF2 activation and miR-34a inhibition in SH-SY5Y cells. Front Cell Neurosci. 9, 209 (2015).

82. Beaulieu, J.-M., Gainetdinov, R. R. \& Caron, M. G. The Akt-GSK-3 signaling cascade in the actions of dopamine. Trends Pharm. Sci. 28, 166-172 (2007).

83. Gould, T. D., Chen, G. \& Manji, H. K. In vivo evidence in the brain for lithium inhibition of glycogen synthase kinase-3. Neuropsychopharmacol. Publ. Am. Coll. Neuropsychopharmacol. 29, 32-38 (2004)

84. O'Brien, W. T. et al. Glycogen synthase kinase-3beta haploinsufficiency mimics the behavioral and molecular effects of lithium. J. Neurosci. J. Soc Neurosci. 24, 6791-6798 (2004).

85. Jope, R. S. \& Johnson, G. V. W. The glamour and gloom of glycogen synthase kinase-3. Trends Biochem Sci. 29, 95-102 (2004).

86. Gould, T. D. et al. Beta-catenin overexpression in the mouse brain phenocopies lithium-sensitive behaviors. Neuropsychopharmacol. Publ. Am. Coll. Neuropsychopharmacol. 32, 2173-2183 (2007).

87. Gould, T. D. et al. Generation and behavioral characterization of beta-catenin forebrain-specific conditional knock-out mice. Behav. Brain Res. 189, 117-125 (2008).

88. Gould, T. D., Quiroz, J. A., Singh, J., Zarate, C. A. \& Manji, H. K. Emerging experimental therapeutics for bipolar disorder: insights from the molecular and cellular actions of current mood stabilizers. Mol. Psychiatry 9, 734-755 (2004)

89. Barthel, A., Schmoll, D. \& Unterman, T. G. FoxO proteins in insulin action and metabolism. Trends Endocrinol. Metab. TEM. 16, 183-189 (2005).

90. Almeida, M., Ambrogini, E., Han, L., Manolagas, S. C. \& Jilka, R. L. Increased lipid oxidation causes oxidative stress, increased peroxisome proliferator-activated receptor-gamma expression, and diminished pro-osteogenic Wht signaling in the skeleton. J. Biol. Chem. 284, 27438-27448 (2009).

91. Essers, M. A. G. et al. Functional interaction between beta-catenin and FOXO in oxidative stress signaling. Science. 308, 1181-1184 (2005).

92. Hoogeboom, D. et al. Interaction of FOXO with beta-catenin inhibits betacatenin/T cell factor activity. J. Biol. Chem. 283, 9224-9230 (2008).

93. Mao, Z., Liu, L., Zhang, R. \& Li, X. Lithium reduces FoxO3a transcriptional activity by decreasing its intracellular content. Biol. Psychiatry 62, 1423-1430 (2007).
94. Shao, L., Young, L. T. \& Wang, J.-F. Chronic treatment with mood stabilizers lithium and valproate prevents excitotoxicity by inhibiting oxidative stress in rat cerebral cortical cells. Biol. Psychiatry 58, 879-884 (2005).

95. de Vasconcellos, A. P. S. et al. Chronic lithium treatment has antioxidant properties but does not prevent oxidative damage induced by chronic variate stress. Neurochem Res. 31, 1141-1151 (2006).

96. Cui, J., Shao, L., Young, L. T. \& Wang, J.-F. Role of glutathione in neuroprotective effects of mood stabilizing drugs lithium and valproate. Neuroscience 144, 1447-1453 (2007)

97. Frey, B. N. et al. Increased oxidative stress and DNA damage in bipolar disorder: a twin-case report. Prog. Neuropsychopharmacol. Biol. Psychiatry 31, 283-285 (2007).

98. Machado-Vieira, R. et al. Oxidative stress parameters in unmedicated and treated bipolar subjects during initial manic episode: a possible role for lithium antioxidant effects. Neurosci. Lett. 421, 33-36 (2007).

99. Kim, Y.-H., Rane, A., Lussier, S. \& Andersen, J. K. Lithium protects against oxidative stress-mediated cell death in a-synuclein-overexpressing in vitro and in vivo models of parkinson's disease. J. Neurosci. Res. 89, 1666-1675 (2011).

100. Halleskog, C. et al. WNT signaling in activated microglia is proinflammatory. Glia 59, 119-131 (2011)

101. L'episcopo, F. et al. A Wnt1 regulated frizzled-1/ß-catenin signaling pathway as a candidate regulatory circuit controlling mesencephalic dopaminergic neuron-astrocyte crosstalk: herapeutical relevance for neuron survival and neuroprotection. Mol. Neurodegener. 6, 49 (2011).

102. Ma, B. \& Hottiger, M. O. Crosstalk between Wnt/ $\beta$-catenin and NF-kB signaling pathway during inflammation. Front Immunol. 7, 378 (2016).

103. Mitchell, S., Vargas, J. \& Hoffmann, A. Signaling via the NFkB system. Wiley Interdiscip. Rev. Syst. Biol. Med. 8, 227-241 (2016).

104. Deng, J. et al. beta-catenin interacts with and inhibits NF-kappa $B$ in human colon and breast cancer. Cancer Cell. 2, 323-334 (2002).

105. Liu, J. et al. PI3K is required for the physical interaction and functional inhibition of NF-kB by $\beta$-catenin in colorectal cancer cells. Biochem Biophys. Res Commun. 434, 760-766 (2013).

106. Martin, M., Rehani, K., Jope, R. S. \& Michalek, S. M. Toll-like receptor-mediated cytokine production is differentially regulated by glycogen synthase kinase 3 . Nat. Immunol. 6, 777-784 (2005).

107. Manicassamy, S. et al. Activation of beta-catenin in dendritic cells regulates immunity versus tolerance in the intestine. Science. 329, 849-853 (2010).

108. Cho, H. H. et al. Differential effect of NF-kappaB activity on beta-catenin/Tcf pathway in various cancer cells. FEBS Lett. 582, 616-622 (2008).

109. Fliniaux, I., Mikkola, M. L., Lefebvre, S. \& Thesleff, I. Identification of dkk4 as a target of Eda-A1/Edar pathway reveals an unexpected role of ectodysplasin as inhibitor of Wnt signalling in ectodermal placodes. Dev. Biol. 320, 60-71 (2008).

110. Rodríguez de la Concepción, M. L., Yubero, P., Iglesias, R., Giralt, M. \& Villarroya F. Lithium inhibits brown adipocyte differentiation. FEBS Lett. 579, 1670-1674 (2005).

111. Lee, C.-H., Olson, P. \& Evans, R. M. Minireview: lipid metabolism, metabolic diseases, and peroxisome proliferator-activated receptors. Endocrinology 144 2201-2207 (2003).

112. Marx, N., Duez, H., Fruchart, J.-C. \& Staels, B. Peroxisome proliferator-activated receptors and atherogenesis: regulators of gene expression in vascular cells. Circ. Res. 94, 1168-1178 (2004).

113. Cunard, R. et al. Regulation of cytokine expression by ligands of peroxisome proliferator activated receptors. J. Immunol. Balt. Md. 1950 168, 2795-2802 (2002).

114. Ricote, M., Li, A. C., Willson, T. M., Kelly, C. J. \& Glass, C. K. The peroxisome proliferator-activated receptor-gamma is a negative regulator of macrophage activation. Nature. 391, 79-82 (1998).

115. Giannini, S., Serio, M. \& Galli, A. Pleiotropic effects of thiazolidinediones: taking a look beyond antidiabetic activity. J. Endocrinol. Invest. 27, 982-991 (2004)

116. Vallée, A., Lecarpentier, Y., Guillevin, R. \& Vallée, J.-N. Thermodynamics in gliomas: interactions between the canonical WNT/beta-catenin pathway and PPAR gamma. Front Physiol. 8, 352 (2017).

117. Vallée A., Lecarpentier Y., Guillevin R., Vallée J.-N. Demyelination in multiple sclerosis: reprogramming energy metabolism and potential PPARY agonist treatment approaches. Int. J.Mol. Sci. 2018; https://doi.org/ 10.3390/ijms19041212. 
118. Park, K. S. et al. Neuronal differentiation of embryonic midbrain cells by upregulation of peroxisome proliferator-activated receptor-gamma via the JNK-dependent pathway. Exp. Cell Res. 297, 424-433 (2004).

119. Vallée, A. \& Vallée, J.-N. Warburg effect hypothesis in autism Spectrum disorders. Mol. Brain. 11, 1 (2018).

120. Grimes, C. A. \& Jope, R. S. The multifaceted roles of glycogen synthase kinase 3beta in cellular signaling. Prog. Neurobiol. 65, 391-426 (2001).

121. Jeon, M., Rahman, N. \& Kim, Y.-S. Wnt/B-catenin signaling plays a distinct role in methyl gallate-mediated inhibition of adipogenesis. Biochem Biophys. Res Commun. 479, 22-27 (2016).

122. Gustafson, B., Eliasson, B. \& Smith, U. Thiazolidinediones increase the wingless-type MMTV integration site family (WNT) inhibitor Dickkopf-1 in adipocytes: a link with osteogenesis. Diabetologia 53, 536-540 (2010).

123. Basu, A. \& Haldar, S. The relationship between Bcl2, Bax and p53: consequences for cell cycle progression and cell death. Mol. Hum. Reprod. 4 1099-1109 (1998).

124. Chen, R. W. \& Chuang, D. M. Long term lithium treatment suppresses $p 53$ and Bax expression but increases $\mathrm{BCl}-2$ expression. A prominent role in neuroprotection against excitotoxicity. J. Biol. Chem. 274, 6039-6042 (1999).

125. Chen, G., Rajkowska, G., Du, F., Seraji-Bozorgzad, N. \& Manji, H. K. Enhancement of hippocampal neurogenesis by lithium. J. Neurochem 75, 1729-1734 (2000).

126. Youdim, M. B. H. \& Arraf, Z. Prevention of MPTP (N-methyl-4-phenyl-1,2,3,6tetrahydropyridine) dopaminergic neurotoxicity in mice by chronic lithium: involvements of Bcl-2 and Bax. Neuropharmacology 46, 1130-1140 (2004).

127. Ruvolo, P. P., Deng, X.\& May, W. S. Phosphorylation of $\mathrm{Bcl} 2$ and regulation of apoptosis. Leukemia 15, 515-522 (2001).

128. Chen, C.-L., Lin, C.-F., Chiang, C.-W., Jan, M.-S. \& Lin, Y.-S. Lithium inhibits ceramide- and etoposide-induced protein phosphatase 2A methylation, BCl2 dephosphorylation, caspase-2 activation, and apoptosis. Mol. Pharm. 70, 510-517 (2006).
129. Chen, R.-W. et al. Regulation of c-Jun N-terminal kinase, p38 kinase and AP-1 DNA binding in cultured brain neurons: roles in glutamate excitotoxicity and lithium neuroprotection. J. Neurochem. 84, 566-575 (2003).

130. Abousaab, A. \& Lang, F. Up-regulation of excitatory amino acid transporters EAAT3 and EAAT4 by lithium sensitive glycogen synthase kinase GSK3ß. Cell Physiol. Biochem Int. J. Exp. Cell Physiol. Biochem Pharm. 40, 1252-1260 (2016).

131. Dixon, J. F. \& Hokin, L. E. Lithium acutely inhibits and chronically up-regulates and stabilizes glutamate uptake by presynaptic nerve endings in mouse cerebral cortex. Proc. Natl Acad. Sci. USA 95, 8363-8368 (1998).

132. Mayer, M. L. \& Miller, R. J. Excitatory amino acid receptors, second messengers and regulation of intracellular $\mathrm{Ca} 2+$ in mammalian neurons. Trends Pharm. Sci. 11, 254-260 (1990).

133. Yoshii, A. \& Constantine-Paton, M. Postsynaptic BDNF-TrkB signaling in synapse maturation, plasticity, and disease. Dev. Neurobiol. 70, 304-322 (2010).

134. Scheuing, L., Chiu, C.-T., Liao, H.-M. \& Chuang, D.-M. Antidepressant mechanism of ketamine: perspective from preclinical studies. Front Neurosci. 9. 249 (2015).

135. Chiu C.-T., et al. The mood stabilizer lithium potentiates the antidepressantlike effects and ameliorates oxidative stress induced by acute ketamine in a mouse model of stress. Int. J. Neuropsychopharmacol 2014; https://doi.org/ 10.1093/ijnp/pyu102.

136. Chiu, C.-T. \& Chuang, D.-M. Molecular actions and therapeutic potential of lithium in preclinical and clinical studies of CNS disorders. Pharm. Ther. 128, 281-304 (2010).

137. Zeng, Y. et al. Hyperbaric oxygen preconditioning protects cortical neurons against oxygen-glucose deprivation injury: role of peroxisome proliferatoractivated receptor-gamma. Brain Res. 1452, 140-150 (2012).

138. Heneka, M. T. \& Landreth, G. E. PPARs in the brain. Biochim Biophys. Acta. 1771, 1031-1045 (2007). 